\title{
The association between depressive symptoms and physical status including physical activity, aerobic and muscular fitness tests in children
}

\author{
Samad Esmaeilzadeh ${ }^{1}$
}

Received: 2 May 2015/Accepted: 29 July 2015/Published online: 12 August 2015

(C) The Japanese Society for Hygiene 2015

\begin{abstract}
Objectives The aims of the study were to explore the association between depressive symptoms (DS), physical activity (PA), aerobic and muscular fitness in a sample of children.

Methods Four hundred and fifty-six schoolboys aged 7-11-year-old underwent standard anthropometry and various physical fitness tests (e.g., aerobic fitness, strength, speed, power, agility and flexibility). DS and PA were obtained by questionnaires.

Results After adjustment for potential confounders (e.g., age, socioeconomic status and adiposity), PA was significantly and negatively related to DS $(P<0.05)$. Among the physical fitness tests, just time in one-mile run/walk was significantly related to DS $(P<0.05)$.

Conclusion Physical activity and aerobic fitness were significantly correlated with DS; however, no significant relationship was observed between DS and the muscular fitness tests in the children.
\end{abstract}

Keywords Depressive symptoms - Muscular fitness · One-mile run/walk

$\begin{array}{ll}\text { Abbreviations } \\ \text { BMI } & \text { Body mass index } \\ \text { CRF } & \text { Cardiorespiratory fitness } \\ \text { PA } & \text { Physical activity } \\ \text { SES } & \text { Socioeconomic status }\end{array}$

Samad Esmaeilzadeh

samad_esmaeilzadeh@uma.ac.ir; samad.esmaeilzade@yahoo.com

1 Physical activity and exercise science, University of Mohaghegh Ardabili, Ardabil, Iran

\author{
CDI Children's depression inventory \\ PAQ-C PA Questionnaire-Children \\ DS Depressive symptoms
}

\section{Introduction}

Depression has been shown one of the more serious forms of illness in childhood, and depressive episodes may lead to potential life-threatening outcomes [1], and it has been reported that rate of psychological illness in children and adolescents is increasing [2]. It is very possible that adults developing depression initiated by minor depressive symptoms (DS) in childhood, while minor depression in childhood/adolescence has been reported with an increased risk for developing bipolar disorder and substance abuse [3-5]. Depression in childhood and adolescence is reported to be associated with an enhanced risk of suicidal behavior, or is the leading risk factor for suicide $[6,7]$.

Several factors have been shown to be associated with DS. For instance, some researchers have reported that daily physical activity (PA) decreases DS in children [8, 9]. However, although the effect of PA on mental health has been the subject of research for several decades, nonetheless, there is a lack of studies investigating the association between different components of physical fitness, including both cardiorespiratory fitness (CRF) and muscular fitness (e.g., strength, speed, power, agility, etc.) and DS [10, 11], especially among children [12]. For instance, significant cross-sectional and prospective relationships have been shown between CRF and mental health [12-14], and some have reported that high CRF protects against the development of DS [15-17]. However, some researchers have 
reported that self-reported PA but not CRF is related to lower DS in men and women $[18,19]$, and some others reported equivalent results [20, 21]. In addition, some previous studies based on the relationship between DS and PA/fitness did not adjust their analysis for some potential confounders, such as age, adiposity and socioeconomic status (SES) that might confound the associations [14, 17, 19, 22, 23].

The aims of the current study were to explore the crosssectional associations between DS, PA, and physical fitness including both CRF and muscular fitness (e.g., strength, speed, power, agility and flexibility), while adjusting for possible potential confounders (e.g., age, adiposity and SES) in a sample of children.

\section{Methods}

\section{Participants and procedure}

In 2013-2014, this cross-sectional study's data were drawn from a sample of four hundred and fifty six 7-11-year-old schoolboys. Three schools were selected randomly from a list of boys' urban public elementary schools (total number $=60$ ) in the center of Ardabil Province, North West of the Iran. At the second stage, classes in each school were selected randomly and boys of the selected classes (28 classes, total number of candidate children $=707$ ) were invited to the study. Exclusion criteria were as follows: known presence of chronic disease and musculoskeletal injury that prevent the children from performing the fitness tests. Children who were invited and passed the exclusion criteria of the study and gave their consent verbally $(n=609)$ were given a written consent form for their parents approval. 560 signed consent forms were collected and the owners were recruited in the study. However, at the end of the study, complete data were collected from 456 participants (dropped data because of absence, illness, withdrawal of the study for some personal reasons, etc.). Age of the participants was determined from their date of birth in their school register. Measuring of anthropometric variables was done in an empty room, when the participants were at rest. The physical fitness tests that children underwent were carried out during regularly scheduled physical education lessons. All measurements were done during the fall-spring (9 months) of the year 2013-2014. The present study was approved by the Human Ethics Committee of the Ardabil Department of Education, and the experiment was performed in accordance with the ethical standards of the committee and with the Helsinki declaration. All the children volunteered for the present study and informed consents according to the rules of the department were acquired from all the participants in written and parents' signed form. General characteristics of the participants are shown in the Table 1 .

\section{Aerobic and muscular fitness}

The children underwent seven physical fitness tests according to standard methods [24-27]. In the present study, one-mile run/walk test was used for measuring aerobic fitness; while rest of the fitness tests were used for measuring muscular fitness of the children.

One-mile walk/run test This test was used to assess aerobic fitness. The objective of the one-mile run/walk test was to cover a mile in the shortest time possible. The children were encouraged to run throughout the test and to take walking breaks only as needed. The children were also reminded to avoid starting too fast to avoid premature fatigue. Performance in the one-mile run/walk test has been correlated with $\mathrm{VO}_{2 \max }$ and validated for children [27].

Sit and reach Participants sat on the ground with straight legs against a standard reach box with $23 \mathrm{~cm}$ marked at the level of the feet. They were instructed to reach smoothly forward and sustain in the extreme reach position for $2 \mathrm{~s}$. This test measures the flexibility of the hamstrings, buttocks, and lower back [26].

Hand grip strength test This test was used to assess static strength of the boys. It was done by squeezing a calibrated digital hand dynamometer (Takei A5001 Japan) as forcefully as possible with the dominant hand [26].

$4 \times 10 \mathrm{~m}$ shuttle run test This test was used for measuring speed of movement, agility and coordination assessment. On command, the subject run across to pick

Table 1 Characteristics of the boys $(n=456)$

\begin{tabular}{ll}
\hline & Mean (SD) \\
\hline Age (years) & $9.3(1.2)$ \\
Height $(\mathrm{cm})$ & $134.0(8.9)$ \\
Weight $(\mathrm{kg})$ & $31.9(7.6)$ \\
$(\%)$ Fat & $23.0(7.5)$ \\
BMI $\left(\mathrm{kg} / \mathrm{m}^{2}\right)$ & $16.8(2.7)$ \\
DS $(\mathrm{score})$ & $10.5(5.3)$ \\
PA (score) & $2.3(1.4)$ \\
One-mile run/walk $(\mathrm{s})$ & $669.5(120.0)$ \\
Grip strength $(\mathrm{kg})$ & $19.2(6.0)$ \\
Run speed $(\mathrm{s})$ & $6.7(0.8)$ \\
$4 \times 9$ agility $(\mathrm{s})$ & $12.8(1.1)$ \\
Long jump $(\mathrm{cm})$ & $118.6(24.2)$ \\
Sit and reach $(\mathrm{cm})$ & $28.1(6.3)$ \\
Pull ups $(n)$ & $9.1(6.4)$ \\
\hline
\end{tabular}

$B M I$ body mass index, $D S$ depressive symptoms, $P A$ physical activity 
up one block or bag and return to place it behind the starting line, and again run back to pick up the second block or bag and run towards and across the starting line [24].

Modified pull ups To measure upper arm and shoulder girdle strength and muscular endurance [27].

Standing long jump Jumping for distance from a standing start was used to measure explosive strength [26].

$30 \mathrm{~m}$ sprint (from standing position) This test was used for measuring speed of movement.

The agility, run speed, sit and reach and long jump tests were performed twice, and the fastest time or better performance was recorded. A hand held stop-watch was used for recording time to the nearest $0.01 \mathrm{~s}$ (Joerex, ST4610-2, China).

\section{Depressive symptoms (DS)}

Children's depression inventory (CDI), a reliable and wellvalidated twenty-seven item questionnaire with total scores ranging from 0 to 54 , was completed by the boys, to assess DS [28]. The boys had to choose the best description for themselves among three statements with different severity (score 0-2), which belong to each item of the questionnaire. The boys were recommended to fill out the CDI questionnaire by their parents' supervision. Although a new CDI version has been introduced, because it has not been validated in Iranian children, therefore, older version of CDI, which has been validated and used in both Iranian and Arabian children [29-31], was used in the study. The CDI is the most widely used measure of DS in children, with good support for its reliability and validity [32, 33].

\section{Physical activity (PA)}

PA for children was measured using the PA QuestionnaireChildren (PAQ-C) [34, 35] with some alternations according to our society [12]. For example, some sports and games (such as baseball, softball, rowing or canoeing, ice hockey or ringette, cross-country skiing, ice skating) were exchanged with some local games. The PAQ-C is used to assess the PA behaviors of the participants at different times and places (i.e., during school, after school, recess, weekend, etc.) during the previous 7 days. Scoring is based on a 5-point Likert type scale, with an overall PA score derived from the mean of each scored item. Higher levels of PA are indicated by greater scores and vice versa. The PAQ-C has been tested and re-tested, and results have indicated that the questionnaire is reliable and valid measure of PA for children during the school year. Moderately high validity coefficients have been reported for the questionnaire when compared to a variety of criterion measures, including activity ratings, recall questionnaires, and activity monitors ( $r=0.39-0.63)$ [34]. The test-retest reliability for the PAQ-C ranged from $r=0.75-0.82$ and internal consistency reliability values (coefficient alpha) ranged from 0.81 to 0.86 [36]. This questionnaire is widely used in research, in order to assess PA of large and small populations at low cost [35]. Children were recommended to fill out the PAQ-C by their parents' supervision.

\section{Possible covariates/confounders}

\section{Anthropometric variables}

Weight was measured in underwear and without shoes with an electronic scale (Type SECA 861, Germany) to the nearest $0.1 \mathrm{~kg}$, and height was measured barefoot in the Frankfurt horizontal plane with a telescopic height measuring instrument (Type SECA 225, Germany) to the nearest $1 \mathrm{~mm}$. Subcutaneous fat percentage was measured as a reliable overall obesity index than body mass index (BMI) in the children [37, 38]. Lange skinfold calipers were used to assess triceps (vertical fat fold taken midway between the olecranon process and acromion process on the posterior aspect of the arm) and calf (vertical skinfold taken on the medial aspect of the calf at the point of largest circumference) skinfold thickness [39]. All measurements were taken on the right side of the body. The average of three measures was calculated for each site and the following equation was used to predict percent fat [39]:

Boys : \% fat $=0.735$ (sum of average skinfolds $)+1.0$

\section{Socioeconomic status (SES)}

SES was computed from parents' education and occupational status. Monthly household income was collected in the following Iranian Rial categories (note US \$1 equals approximately to 34000 Rial in Iran): $1 \leq 4000000$ Rial; $2=4000000-8000000$ Rial; $\quad 3=8000000-12000000$ Rial; $\quad 4=12000000-16000000$ Rial; $\quad 5=16000000$ 20000000 Rial; $\quad 6=20000000-25000000$ Rial; $\quad 7=$ 25000000-30000000 Rial; $8=30000000-40000000$ Rial; $9=40000000-50000000$ Rial; $10 \geq 50000000$ Rial.

The highest educational level attained by either parent was collapsed into the following categories: $0=$ no education; $1=$ elementary; $2=$ secondary $3=$ some high school $4=$ completed high school; $5=$ bachelor degree $6=$ Master of Science/Arts; $7=$ PhD, Doctoral, etc.

In cases where SES scores were available for both parents, the mean was used. Self-administered questionnaire which was answered by the boys' parents was used for obtaining parents' education and occupational status. 


\section{Data analysis}

Descriptive statistics were run on all variables. Before further analysis, all data were checked for normality by Kolmogorov-Smirnov test, and appropriate transformations using natural logarithm (transformation by exponential value) were applied when necessary. Initial Pearson product-moment correlations were conducted on DS, demographic variables (age and SES), \%fat, PA score and the physical fitness variables. Any variable exhibiting a significant correlation with the dependent variable (DS) was included as a covariate/confounder in the multiple linear regression analyses. Hierarchical linear regression analyses were conducted as follows: age, SES and \%fat (significant demographic variables; according to results of Table 2) were included in the first step of the regression analyses and PA was added into the second step and each of the physical fitness variables was added into the third step of the analysis, separately. All calculations were performed using SPSS v.21.0 software for Windows. The significance level was set at $P<0.05$.

\section{Results}

Pearson product-moment correlation analyses (Table 2) demonstrated a significant correlation of DS with age, SES, BMI, \%fat, PA, one-mile run/walk, grip strength and long jump $(P<0.05)$.
Multiple regression analysis (Table 3) revealed significant relationship of DS with age, \%fat and PA (step 2; $P<0.05)$. Among the physical fitness variables, just introducing time in one-mile run/walk had significant effect on the model (F change $=23.9 ; P<0.001$ ) and showed significant relationship with DS (standardized $\beta=0.37 ; P<0.001)$. None of the muscular fitness was significantly correlated to DS and introducing them to the model had no significant effect $(P>0.05)$.

\section{Discussion}

The result of significant relationship between DS and PA is consistent with results of both cross-sectional and longitudinal studies $[8,9,12,18,19,22]$. According to the "protection hypothesis," it has been suggested that PA protects against depressed mood and several biological and psychological mechanisms [40]. For instance, the hypotheses propose that PA provides experiences of mastery and control, is a distractor from everyday stressors and negative thoughts, influences self-esteem, and improves the retrieval of positive thoughts [41]. Nonetheless, it should be stated that it is very possible depressed mood disable person to be physically active [42], and also some longitudinal studies have failed to indicate significant effect of PA on DS [40]. A recent systematic review concluded that based on little currently evidence, the effectiveness of exercise on treatment of major depression is still unknown,

Table 2 Pearson correlation among the study variables

\begin{tabular}{|c|c|c|c|c|c|c|c|c|c|c|c|c|c|}
\hline & & 2 & 3 & 4 & 5 & 6 & 7 & 8 & 9 & 10 & 11 & 12 & 13 \\
\hline 1. & DS & $0.19^{* *}$ & $-0.11^{*}$ & $0.15 * *$ & $0.15 * *$ & $-0.11^{*}$ & $0.25 * *$ & $0.19 * *$ & 0.09 & -0.087 & $0.1^{*}$ & -0.00 & -0.05 \\
\hline 2. & Age & & 0.03 & $0.32 * *$ & $0.30 * *$ & $0.08 *$ & $-0.14 * *$ & $0.72 * *$ & $-0.53 * *$ & $-0.67 * *$ & $0.65 * *$ & $-0.16 * *$ & 0.01 \\
\hline 3. & SES & & & 0.06 & 0.08 & 0.03 & 0.01 & -0.05 & -0.08 & -0.002 & 0.05 & -0.06 & -0.07 \\
\hline 4. & $\%$ Fat & & & & $0.85 * *$ & $-0.12 * *$ & $0.42 * *$ & $0.50 * *$ & -0.02 & -0.07 & -0.06 & $-0.08 *$ & $-0.32 * *$ \\
\hline 5. & BMI & & & & & $-0.13 * *$ & $0.42 * *$ & $0.52 * *$ & -0.02 & $-0.10^{*}$ & $0.10^{*}$ & 0.01 & $-0.24 * *$ \\
\hline 6. & PA & & & & & & $-0.36^{* *}$ & 0.01 & $-0.35^{* *}$ & $-0.342 * *$ & $0.30 * *$ & $0.14 * *$ & $0.22 * *$ \\
\hline 7. & $\begin{array}{l}\text { One-mile } \\
\text { run }\end{array}$ & & & & & & & -0.03 & $0.41 * *$ & $0.344 * *$ & $-0.37 * *$ & $-0.10^{*}$ & $-0.32 * *$ \\
\hline 8. & $\begin{array}{l}\text { Grip } \\
\text { strength }\end{array}$ & & & & & & & & $-0.47 * *$ & $-0.574 * *$ & $0.59 * *$ & -0.04 & 0.02 \\
\hline 9. & $\begin{array}{l}\text { Run } \\
\text { speed }\end{array}$ & & & & & & & & & $0.680 * *$ & $-0.58 * *$ & -0.00 & $-0.28 * *$ \\
\hline 10. & Agility & & & & & & & & & & $-0.72 * *$ & -0.02 & $-0.26^{* *}$ \\
\hline 11. & $\begin{array}{l}\text { Long } \\
\text { jump }\end{array}$ & & & & & & & & & & & 0.07 & $0.25 * *$ \\
\hline 12. & $\begin{array}{r}\text { Sit and } \\
\text { reach }\end{array}$ & & & & & & & & & & & & $0.25 * *$ \\
\hline 13. & Pull ups & & & & & & & & & & & & \\
\hline
\end{tabular}

* Significant at $<0.05$; ** significant at $<0.01$ 
Table 3 Hierarchical regression analysis between DS, PA and the physical fitness variables

\begin{tabular}{|c|c|c|c|c|}
\hline & Depressive sym & toms & & \\
\hline & Standardized $\beta$ & $R^{2}$ & F change & Adj. $R^{2}$ \\
\hline Step 1 & & 0.07 & $6.1 * *$ & 0.06 \\
\hline Age & $0.15^{*}$ & & & \\
\hline SES & -0.09 & & & \\
\hline$\%$ Fat & $0.16^{*}$ & & & \\
\hline Step 2 & & 0.09 & $4.8^{*}$ & 0.075 \\
\hline Age & $0.16^{*}$ & & & \\
\hline SES & -0.07 & & & \\
\hline$\%$ Fat & $0.14 *$ & & & \\
\hline PA & $-0.15^{*}$ & & & \\
\hline Step 3 & & 0.17 & $23.9 * *$ & 0.15 \\
\hline Age & $0.24 * *$ & & & \\
\hline SES & -0.07 & & & \\
\hline$\%$ Fat & -0.07 & & & \\
\hline PA & -0.04 & & & \\
\hline One-mile run/walk & $0.37 * *$ & & & \\
\hline Step 3 & & 0.067 & 0.03 & 0.055 \\
\hline Age & $0.15^{*}$ & & & \\
\hline SES & -0.1 & & & \\
\hline$\%$ Fat & 0.08 & & & \\
\hline PA & $-0.12 *$ & & & \\
\hline Grip strength & 0.01 & & & \\
\hline Step 3 & & 0.07 & 0.01 & 0.055 \\
\hline Age & $0.15^{*}$ & & & \\
\hline SES & $-0.13 *$ & & & \\
\hline$\%$ Fat & 0.09 & & & \\
\hline PA & $-0.12 *$ & & & \\
\hline Long jump & -0.002 & & & \\
\hline
\end{tabular}

* Significant at $<0.05$; ** significant at $<0.01$

but exercise is beneficial for many other reasons, and in combination with other effective treatments would seem to make sense in the treatment of depression [43].

The results of the study indicated no significant relationship between DS and muscular fitness (e.g., static strength, explosive strength, etc.) in the boys. It should be stated that there is little evidence based on the relationship between DS and different components of physical fitness including both CRF and muscular fitness, especially among children [12], and searching the literature just the relationship of DS with aerobic fitness and static strength was observed. For instance, among young adults, poor hand grip strength reported with increased levels of DS just in men participants (but not women) [11]. In other recent studies among older subjects, high DS were reported with worse hand grip strength [11, 44]. The result of the present study based on the relationship between static strength and DS is not consistent with the previous studies among adults and older people $[10,11,44]$, but is according to the results of a recent study in a sample of children [12]. As it has been demonstrated consistently, higher grip strength is significantly and positively related to higher adiposity in both children and adolescents [24, 25], and higher adiposity is related to higher DS. Therefore, the lack of no significant relationship between DS and higher static strength may be mediated by higher adiposity in the children. However, because of the cross-sectional nature of the study and lack of evidence underlying relationship between DS and muscular fitness, the study is unable to discuss more of the observed relationships.

The results indicated significant relationship between DS and aerobic fitness in the boys. Several studies have shown significant relationship between DS and aerobic fitness [12-17], and some reported that higher CRF may be as a protective factor against the development of DS [1517]. For instance, although significant association has been shown between depression and obesity [45], among homogenous obese adolescents, it was observed that those with elevated DS displayed poorer CRF than those without elevated DS [46]. However, some studies failed to observe significant relationship between CRF and DS [11, 18, 19]. The inconsistency in results of the studies may be because of some methodological, population being studied and covariates included in the studies. CRF is the major component of physical fitness most relevant to an individual's risk of developing metabolic disease [47], and can be highly and positively influenced by regular engagement in moderate-to-high intensity PA [48]. In addition, numerous studies have shown that prescribed PA as a behavior factor can benefit both DS across with physical fitness and obesity $[8,9,18,19,22,49,50]$. Some recent longitudinal studies failed to show relationship between leisure time PA and declined DS among adolescent, but they did not measure CRF changes in their studies [40]. Longitudinal studies reported that promotion of CRF may be an important strategy for preventing depression in adolescents [15-17].

The present study results indicated that obesity was significantly associated with DS in the boys. Although depression and obesity have traditionally been compartmentalized as separate emotional and physical health conditions, interactions and common pathways have been proposed between them [45]. For instance, altered stress system and increased inflammation may be a common link between depression and obesity. Another possible role of serotonin in the relationship between depression and obesity has been suggested recently. However, the relationship between depression and obesity is complex and further longitudinal studies are needed [45].

Although the study has some strengths points such as sample size, considering various variables and potential confounders; nonetheless, because of some limitations of 
the study, results need to be interpreted with caution. For example, the cross-sectional nature of the study limits the possibility to draw conclusions about causality of any of the observed relationships. Using questionnaires for obtaining PA and DS is another limitation of the study; although reliability of the questionnaires has been shown $[33,34]$. Although the physical fitness tests examiners tried to motivate the children for exhibiting their best physical fitness performances, not being in good mood could affect their motivation. Lacking subjects of both sexes is another limitation of the study.

Acknowledgments We thank all participants for their kind participation in the study. No funding was received for performing the present study.

\section{Compliance with ethical standards}

Conflict of interest The author has no conflicts of interest to declare.

\section{References}

1. Lewinsohn RM, Hops H, Roberts RE, Seeley JR, Andrews JA. Adolescent psychopathology: I. Prevalence and incidence of depression and other DSM-III-R disorders in high school students. J Abnorm Psychol. 1993;102(1):133-44.

2. Collishaw S, Maughan B, Goodman R, Pickles A. Time trends in adolescent mental health. J Child Psychol Psychiatry. 2004;45(8):1350-62.

3. Birmaher B, Ryan ND, Williamson DE, Brent DA, Kaufman J. Childhood and adolescent depression: a review of the past 10 years. Part 1. J Am Acad Child Adolesc Psychiatry. 1996;35:1427-39.

4. Klein DN, Schwartz JE, Rose S, Leader JB. Five-year course and outcome of dysthymic disorder: a prospective, naturalistic follow-up study. Am J Psychiatry. 2000;157:931-9.

5. Satala TA, Marttunen M, Henriksson AT, Lonnqvist J. Depressive symptoms in adolescence as predictors of early adulthood depressive disorders and maladjustment. Am J Psychiatry. 2002;159:1235-7.

6. Grinspoon L. (ed) Mood disorders in childhood and adolescencePart I. Harv Mental Health Lett,1993;10(5):1-4.

7. Shaffer D, Gould MS, Fisher P, Trautman P, Moreau D, Kleinman M, Flory M. Psychiatric diagnosis in child and adolescent suicide. Arch Gen Psychiatry. 1996;53:339-48.

8. Jonsdottir IH, Rodjer L, Hadzibajramovic E, Borjesson M, Ahlborg G. A prospective study of leisure-time physical activity and mental health in Swedish health care workers and social insurance officers. Prev Med. 2010;51(5):373-7.

9. Sallis JF. Epidemiology of physical activity and fitness in children and adolescents. Crit Rev Food Sci Nutr. 1993;33:403-8.

10. Rantanen T, Penninx BW, Masaki K, Lintunen T, Foley D, Guralnik JM. Depressed mood and body mass index as predictors of muscle strength decline in old men. J Am Geriatr Soc. 2000;48(6):613-7.

11. Suija K, Timonen M, Suviola M, Jokelainen J, Jarvelin MR, Tammelin $\mathrm{T}$. The association between physical fitness and depressive symptoms among young adults: results of the Northern Finland 1966 birth cohort study. BMC Public Health. 2013;13:535.
12. Esmaeilzadeh S. Relationship between depressive symptoms with physical activity and physical fitness among children. Ment Health Prev. 2014;2:11-7.

13. Hakkinen A, Rinne M, Vasankari T, Santtila M, Hakkinen K, Kyrolainen H. Association of physical fitness with health-related quality of life in Finnish young men. Health Qual Life Outcomes. 2010;8:15.

14. Tomson LM, Pangrazi RP, Friedman G, Hutchison N. Childhood depressive symptoms, physical activity and health related fitness. J Sport Exerc Psychol. 2003;25:419-39.

15. Aberg MA, Waern M, Nyberg J, Pedersen NL, Bergh Y, Aberg ND, et al. Cardiovascular fitness in males at age 18 and risk of serious depression in adulthood: Swedish prospective populationbased study. Br J Psychiatry. 2012;201(5):352-9.

16. Boettger S, Wetzig F, Puta C, Donath L, Muller HJ, Gabriel HH, Bar KJ. Physical fitness and heart rate recovery are decreased in major depressive disorder. Psychosom Med. 2009;71:519-23.

17. Sui X, Laditka JN, Church TS, Hardin JW, Chase N, Davis K, Blair S. Prospective study of cardiorespiratory fitness and depressive symptoms in women and men. J Psychiatry Res. 2009;43:546-52.

18. Lindwall M, Ljung T, Hadzibajramovi E, Jonsdottir IH. Selfreported physical activity and aerobic fitness are differently related to mental health. Ment Health Phys Act. 2012;5:28-34.

19. Thirlaway K, Benton D. Participation in physical activity and cardiovascular fitness have different effects on mental health and mood. J Psychosom Res. 1992;36(7):657-65.

20. Tolmunen T, Laukkanen JA, Hintikka J, Kurl S, Viinamaki H, Salonen R, et al. Low maximal oxygen uptake is associated with elevated depressive symptoms inmiddle-agedmen. Eur J Epidemiol. 2006;21(9):701-6.

21. Valtonen M, Laaksonen DE, Laukkanen J, Tolmunen T, Rauramaa R, Viinamaki H, et al. Leisure-time physical activity, cardiorespiratory fitness and feelings of hopelessness in men. BMC Public Health. 2009;9:204.

22. Raudsepp L, Neissaar I. Brief report: relationships between physical activity and depressive symptoms in adolescent girls. J Adolesc. 2012;35:1399-402.

23. Ussher MH, Owen CG, Cook DG, Whincup PH. The relationship between physical activity, sedentary behaviour and psychological wellbeing among adolescents. Soc Psychiatry Psychiatr Epidemiol. 2007;42:851-6.

24. Esmaeilzadeh S, Ebadollahzadeh K. Physical fitness, physical activity and sedentary activities of 7-11 year old boys with different Body Mass Indexes. Asian J Sports Med. 2012;3(2): $105-12$.

25. Esmaeilzadeh S, Kalantari H. Physical fitness, physical activity, sedentary behavior and academic performance among adolescent boys in different weight statuses. Med J Nutr Metab. 2013;6:207-16.

26. Adam C, Klissouras V, RavazzoloM, Renson R, Tuxworth W. EUROFIT: European test of physical fitness. Rome: Council of Europe, Committee for the Development of Sport; 1988.

27. Welk GJ, Meredith MD. Fitnessgram/activitygram reference guide. 3rd ed. Dallas: The Cooper Institute; 2008.

28. Kovacs M. Manual for the children's depression inventory (CDI). Norton: Multihealth System; 1992.

29. Dehghani F, Amiri S, Molavi H, Neshat-Doost HT. Psychometric properties of the Persian version of the screen for child anxietyrelated emotional disorders (SCARED). J Anxiety Disord. 2013;27(5):469-74.

30. Dehshiri GH, Najafi M, Sheykh M, Habibi A. Investigating primary psychometric properties of children's depression inventory (CDI). J Fam Res. 2009;5(2):159-77 (Persian).

31. Ghareeb A, Beshai JA. Arabic version of the children's depression inventory: reliability and validity. J Clin Psychol. 1989;18(4):323-9. 
32. Al-Balhan EM. The children's depression inventory as a reliable measure for post-Iraqi invasion Kuwaiti Youth. Soc Behavr Pers. 2006;34(4):351-5.

33. Curry JF, Craighead WE. Depression. In: Ollendick TH, Hersen M, editors. Handbook of child and adolescent assessment. Nedham Heights: Allyn and Bacon; 1993. p. 251-68.

34. Kowalski KC, Crocker PRE, Faulkner RA. Validation of the physical activity questionnaire for older children. Pediatr Exerc Sci. 1997;9:174-86.

35. Kowalski KC, Crocker PRE, Donen RMD. The physical activity questionnaire for older children (PAQ-C) and adolescents (PAQA) manual. College of Kinesiology, University of Saskatchewan, Canada; 2004.

36. Crocker PRE, Bailey DA, Faukner RA, Kowalski KC, McGrath R. Measuring general levels of physical activity: preliminary evidence for the physical activity questionnaire for older children. Med Sci Sports Exerc. 1997;29:1344-9.

37. Nooyens AC, Koppes LL, Visscher TL, Twisk JW, Kemper HC, Schuit AJ, et al. Adolescent skinfold thickness is a better predictor of high body fatness in adults than is body mass index: the Amsterdam growth and health longitudinal study. Am J Clin Nutr. 2007;85:1533-9.

38. Sarría A, García-Llop LA, Moreno LA, Fleta J, Morellón MP, Bueno M. Skinfold thickness measurements are better predictors of body fat percentage than body mass index in male Spanish children and adolescents. Eur J Clin Nutr. 1998;52(8):573-6.

39. Roche A, Heymsfield SB, Lohman TE, editors. Body composition. Champaign: Human Kinetics; 1996.

40. Birkeland MS, Torsheim T, Wold B. A longitudinal study of the relationship between leisure-time physical activity and depressed mood among adolescents. Psychol Sport Exer. 2009;10:25-34.
41. Salmon P. Effects of physical exercise on anxiety, depression, and sensitivity to stress: a unifying theory. Clin Psychol. 2001;21:33-61.

42. Goodwin RD. Association between physical activity and mental disorders among adults in the United States. Prev Med. 2003;36:698-703.

43. Cipriani A, Barbui C, Butler R, Hatcher S, Geddes J. Depression in adults: drug and physical treatments. BMJ Clin Evid. 2011;25:1003.

44. Van-Millingen BA, Lamers F, de Hoop GT, Smit JH, Penninx BWJH. Objective physical functioning in patients with depressive and/or anxiety disorder. J Affect Disord. 2011;131:193-9.

45. Reeves GM, Postolache TT, Snitker S. Childhood obesity and depression: connection between these growing problems in growing children. Int $\mathrm{J}$ Child Health Hum Dev. 2008;1(2):103-14.

46. Shomaker LB, Tanofsky-Kraff M, Zocca JM, Field SE, Drinkard B, Yanovski JA. Depressive symptoms and cardiorespiratory fitness in obese adolescents. J Adolesc Health. 2012;50:87-92.

47. LaMonte MJ, Blair SN, Church TS. Physical activity and diabetes prevention. J Appl Physiol. 2005;99:1205-13.

48. Ortega FB, Ruiz JR, Castillo MJ, Sjöström M. Physical fitness in childhood and adolescence: a powerful marker of health. Int $\mathrm{J}$ Obes Lond. 2008;32:1-11.

49. Hamer M, Stamatakis E. Objectively assessed physical activity, fitness and subjective wellbeing. Ment Health Phys Act. 2010;3(2):67-71.

50. Lee DC, Sui X, Ortega FB, Kim YS, Church TS, Winett RA, et al. Comparisons of leisure-time physical activity and cardiorespiratory fitness as predictors of all-cause mortality in men and women. Br J Sports Med. 2011;45(6):504-10. 